\title{
DIÁlOGO ENTRE PESQUISAS CORRELACIONADAS SOBRE AS CONDIÇÕES DE TRABALHO DOCENTE NOS ANOS FINAIS DO ENSINO FUNDAMENTAL
}

\section{DIALOGUE BETWEEN CORRELATED RESEARCHES ABOUT THE TEACHING CONDITIONS IN THE FINAL YEARS OF PRIMARY SCHOOL}

\author{
Antonio José Fernandes Ricardo ${ }^{1}$ \\ Márcia de Souza Hobold ${ }^{2}$
}

\section{RESUMO}

O presente artigo tem por objetivo dialogar sobre as condições de trabalho docente nos anos finais do Ensino Fundamental, tendo como referência quatro pesquisas realizadas no período compreendido entre 2007 e 2014, encontradas durante o balanço das produções (busca de pesquisas correlacionadas). Além de alertar sobre a escassez de pesquisas sobre a temática condições de trabalho docente nos anos finais do Ensino Fundamental, quando comparadas, as pesquisas apresentam diferenças e semelhanças, evidenciando aspectos recorrentes na rotina diária de professores que atuam em escolas municipais e estaduais de diferentes regiões do Brasil. A partir da leitura das quatro pesquisas e dos resultados por elas apresentados, é possível identificar aspectos recorrentes, como a desvalorização docente, a intensificação do trabalho docente e a flexibilização dos contratos de trabalho, características que se relacionam com a precarização das condições de trabalho docente. Entre os referenciais escolhidos para embasar teoricamente o diálogo proposto, citamos André (2010), Frigotto (2010), Oliveira e Assunção (2010), Borges (2010), Fernandes e Helal (2010) e Marin (2010).

PALAVRAS-CHAVE: Anos finais do Ensino Fundamental - Trabalho Docente - Condições de Trabalho Docente - Precarização das condições de trabalho docente - Proletarização Docente.

\section{ABSTRACT}


This paper aims to dialogue about the teaching conditions in the final years of primary school, with reference to four researches realized in the period between 2007 and 2014, found during the balance of productions (search of correlated researches). In addition besides to alert about the lack of researches on the subject teacher working conditions in the final years of primary schools, when compared, the researches show differences and similarities, demonstrating recurrent aspects in the daily routine of teachers who work in municipal and state schools from different regions from Brazil. From the reading of the four surveys and the results they present, it is possible identify recurrent themes such as teaching devaluation, the intensification of teacher's works and the flexibility of employment contracts, characteristics that relate to the precarious working conditions of teachers. Among the benchmarks chosen to base theoretically the proposed dialogue, we quoted André (2010), Frigotto (2010), Oliveira and Assumption (2010), Borges (2010), Fernandes and Helal (2010) and Marin (2010).

KEYWORDS: Final Years of Elementary Education - Teaching Work - Teacher's Working Conditions - Precarious working conditions of teachers - Teacher Proletarianization.

\section{INTRODUÇÃO}

Conforme a Lei $\mathrm{n}^{\circ}$ 9394, de 20 de dezembro de 1996, que estabelece as Diretrizes e Bases da Educação Nacional, conforme prevê o artigo 11, no item V, cabe aos municípios brasileiros:

[...] oferecer a educação infantil em creches e pré-escolas, e, com prioridade, o ensino fundamental, permitida a atuação em outros níveis de ensino somente quando estiverem atendidas plenamente as necessidades de sua área de competência e com recursos acima dos percentuais mínimos vinculados pela Constituição Federal à manutenção e desenvolvimento do ensino (LDB, p. 4).

Embora, oferecer o Ensino Fundamental seja prioridade do poder público municipal, em alguns estados do Brasil, como Santa Catarina e Goiás, por exemplo, esta etapa da Educação Básica tem sido compartilhada com as escolas da Rede Estadual de Educação. Tal constatação encontra-se na pesquisa realizada por Carvalho (2014), em duas escolas da Rede Estadual de Educação de Goiás, bem como na pesquisa "Condições de trabalho docente 
nos anos finais do Ensino Fundamental”, que está em andamento, realizada junto às escolas da Rede Estadual de Educação em Joinville.

Considerando a oferta do Ensino Fundamental, tanto em escolas municipais como em escolas estaduais de diferentes estados brasileiros, quais seriam as condições de trabalho vivenciadas pelos docentes dos anos finais do Ensino Fundamental? Que semelhanças e/ou diferenças fazem parte dos contextos em que os professores desta etapa da educação básica estão inseridos? Que condições de trabalho permeiam a construção de seu saber docente e que sentidos e significados atribuem às suas ações enquanto profissionais da educação?

Frente aos questionamentos propostos, pretende-se estabelecer neste artigo, um diálogo a partir dos resultados apresentados por quatro pesquisas realizadas no período compreendido entre 2007 e 2014. Além da pesquisa citada anteriormente, aplicada junto aos professores de duas escolas da Rede Estadual de Educação de Goiás, as demais foram realizadas em uma escola municipal de Santa Maria (RG), a outra nas escolas da Rede Municipal de Ensino de Joinville (SC) e a quarta pesquisa em duas escolas municipais de Betim (MG).

Durante a realização de um balanço das produções realizadas no primeiro semestre de 2015, como etapa integrante de uma pesquisa de mestrado intitulada "Condições de Trabalho Docente nos Anos Finais do Ensino Fundamental", que se encontra em desenvolvimento, das pesquisas citadas no parágrafo anterior, apenas quatro reforçam uma realidade apontada anteriormente por André (2010). De acordo com a autora, de 298 estudos analisados em 2007, apenas 10 (3\%) focalizaram as condições de trabalho dos docentes, justificando, portanto, a realização de pesquisas sobre o tema na atualidade.

\section{REFERENCIAL TEÓRICO}

De acordo com Frigotto (2010, p.28), “é no próprio processo histórico de tornarse humano que surge a atividade que denominamos de trabalho como algo específico do homem".

A partir da citação acima, é possível afirmar que, durante o exercício de sua profissão, o professor exerce um tipo de trabalho específico, ou seja, o trabalho docente, que segundo Oliveira (2010, p. 28): 
Trata-se de uma categoria que abarca tanto os sujeitos que atuam no processo educativo nas escolas e em outras instituições de educação, nas suas diversas caracterizações de cargos, funções, tarefas, especialidades e responsabilidades, determinando suas experiências e identidades, quanto às atividades laborais realizadas. Compreende, portanto, as atividades e relações presentes nas instituições educativas, extrapolando a regência de classe.

Embora pareça uma atividade individualizada, se pensado única e exclusivamente o espaço da sala de aula, o trabalho do professor diferencia-se da atividade desenvolvida pelo operário fabril, por exemplo, que operando uma determinada máquina, transforma a matéria prima em produto final. Ao contrário, o trabalho do professor acontece em parceria com outros profissionais, de forma coletiva. De acordo com Borges (2010), pode ser entendido como trabalho coletivo no âmbito da escola:

[...] tudo o que diz respeito ao 'trabalho escolar, entendido aqui como um processo coletivo de trabalho, englobando a totalidade das atividades diferenciadas que assumem e realizam os vários agentes escolares, professores, bem evidentemente, mas também diretores de escola, profissionais técnicos, psicólogos escolares, conselheiros pedagógicos, entre outros (p. 28).

Além da necessidade de diversos profissionais e de seus saberes, também se faz necessária a existência de uma estrutura física que permita à escola dar conta do modelo de educação proposto por ela. Compondo o conjunto de profissionais que com seu saber específico se inserem neste contexto, o docente desenvolve seu ofício frente à existência de condições de trabalho específicas, que podem variar de uma escola para outra. De acordo com Oliveira e Assunção (2010, p. 5):

A noção de condições de trabalho designa o conjunto de recursos que possibilitam a realização do trabalho, envolvendo as instalações físicas, os materiais e insumos disponíveis, os equipamentos e meios de realização das atividades e outros tipos de apoio necessários, dependendo da natureza da produção. Contudo, as condições de trabalho não se restringem ao plano do posto ou local de trabalho ou à realização em si do processo de trabalho, ou seja, o processo que transforma insumos e matériasprimas em produtos, mas diz respeito também às relações de emprego. As condições de trabalho se referem a um conjunto que inclui relações, as quais dizem respeito ao processo de trabalho e às condições de emprego (formas de contratação, remuneração, carreira e estabilidade).

Discutir as condições de trabalho, enquanto conjunto que inclui as relações que envolvem o processo de trabalho e as condições de emprego, permite discutir elementos de 
uma realidade presente em alguns estados brasileiros, realidade esta, marcada pela contínua precarização do trabalho. Fernandes e Helal afirmam que a precarização do trabalho:

Refere-se ao surgimento de novas formas de trabalho a partir de um processo de mudanças estruturais no capitalismo, que procura garantir competitividade às empresas por meio da flexibilização das relações de trabalho. Nesse processo, novas bases institucionais para o desenvolvimento do capitalismo apareceram. O sistema econômico, antes centrado no capital industrial, passou a se basear em modelos flexíveis de produção, com destaque ao capital financeiro. [...] A precarização do trabalho no Brasil tem sido analisada, buscando destacar as alterações no mercado de trabalho - crescimento da informalidade, de formas flexíveis de contratação, e do desemprego em determinados setores e ocupações - e suas implicações para o indivíduo (2010, p. 22).

Discutir a precarização do trabalho remete inevitavelmente à discussão acerca desta precarização sobre as condições de trabalho docente, situação cada vez mais crescente, conforme evidenciado por Marin (2010, p. 22), em levantamento realizado junto ao Banco de Teses e Dissertações da CAPES:

[...] foram encontradas, no período de 1987 a 2009, 61 referências ao tema, quer seja no título, no corpo do trabalho ou nas palavras-chave, quando realizada a busca por 'expressão exata': precarização do trabalho docente ou do trabalho do professor. Surge, a partir de 2002, em conclusão de dissertação sobre educação a distância; em 2004, aparece pela primeira vez na introdução e, em 2005, inicia-se o uso em várias circunstâncias dos trabalhos: título, corpo do texto, palavras-chave.

Ao analisar os diferentes usos e termos relacionados ao trabalho docente ou trabalho do professor e sua relação com a precarização do trabalho docente, a autora afirma que:

Nas caracterizações da precarização do trabalho docente, foram obtidas as seguintes vinculações: quando se refere às mudanças do trabalho, encontra-se flexibilização; intensificação; desemprego; desprofissionalização; degradação; sobrecarga; cobranças; fragilização; desvalorização; competitividade; condições de trabalho e de pesquisa; perda de autonomia (MARIN, 2010, p. 22).

A autora aponta ainda para as consequências decorrentes das alterações nas relações de trabalho percebidas nos trabalhos analisados. Segundo ela:

[...] verificam-se referências a: desgaste; cansaço excessivo; sofrimento; desistência; resistência; adoecimento; isolamento; sentimentos e conflitos nas relações com alunos, pares e gestores; desorganização dos trabalhadores; perda de controle sobre o próprio trabalho; constrangimentos (MARIN, 2010, p. 22). 
Conforme a análise de Marin (2010, p.22) acerca dos trabalhos acima citados, “[...] a imensa maioria dos trabalhos, aqui referidos, estabelece relações com o avanço do neoliberalismo e as políticas públicas educacionais desencadeadas no Brasil entre outros países, com elevada incidência a partir da década de 1990".

Diante das constatações apontadas por Marin (2010), reforçadas pelas pesquisas realizadas por Silva (2007) e Carvalho (2014), o diálogo proposto neste artigo apresenta-se como uma possibilidade de reflexão acerca das condições de trabalho docente vivenciadas pelos professores dos anos finais do Ensino Fundamental, evidenciando a partir da comparação de diferentes pesquisas, semelhanças e diferenças presentes em diferentes contextos.

\section{METODOLOGIA}

Para que a discussão proposta neste artigo fosse possível, fez-se necessário a realização de um balanço das produções, tendo por resultado, o encontro de quatro pesquisas sobre a temática "condições de trabalho docente nos anos finais do Ensino Fundamental".

O levantamento das pesquisas aconteceu por meio de consulta em quatro "locais" distintos, ou seja, no Banco de Dissertações do Programa de Mestrado em Educação da Universidade da Região de Joinville - UNIVILLE, no Banco de Teses e na Biblioteca Digital de Teses e Dissertações - BDTD, ambas da Coordenação de Aperfeiçoamento de Pessoal de Nível Superior - CAPES, na plataforma Scientific Eletronic Library Online - SciELO e nas edições da Associação Nacional de Pós-Graduação e Pesquisa em Educação - ANPEd nacional (23 ${ }^{\mathrm{a}}$ e 36 ) e da região Sul (1998 a 2014). Na pesquisa realizada junto às edições da ANPEd Nacional e da Região Sul, a pesquisa teve como foco os trabalhos apresentados no GT 09 - Trabalho e Educação, no GT 08 - Formação Docente e no GT 13 - Educação Fundamental.

Os descritores empregados durante o levantamento foram: condições de trabalho docente, condições de trabalho docente nos anos finais do Ensino Fundamental, condições de trabalho dos professores nos anos finais do Ensino Fundamental.

Após a leitura das pesquisas, foi possível identificar semelhanças e divergências nas condições de trabalho vivenciadas pelos professores dos anos finais do Ensino 
Fundamental de escolas municipais e estaduais de diferentes regiões, estados e cidades brasileiras. De forma específica, foram identificados fatores que, segundo Marin (2010), caracterizam a precarização das condições de trabalho. Podemos citar a desvalorização docente, a intensificação do trabalho docente e a flexibilização dos contratos de trabalho, conforme se pretende discutir na sequência deste artigo.

\section{O QUE AS PESQUISAS REVELAM?}

A partir das quatro pesquisas encontradas durante o balanço das produções, pretende-se discutir, por meio de uma síntese destes trabalhos, as semelhanças e divergências quanto às condições de trabalho docente nos anos finais do Ensino Fundamental, em escolas estaduais e municipais localizadas em quatro estados brasileiros: Santa Catarina - SC, Rio Grande do Sul - RS, Minas Gerais - MG e Goiás - GO.

$\mathrm{O}$ primeiro estudo aqui relacionado tem como base a pesquisa apresentada na edição de 2010 da ANPEd Sul, no GT 09 (Trabalho e Educação), realizada por Bruna Pereira Alves, Jolair da Costa Silva e Liliana Soares Ferreira, intitulada "Considerações acerca do trabalho de professores a partir de uma investigação com professoras de uma escola municipal de Santa Maria-RS”. Ao explicitar os fatores que contribuíram para a escolha profissional das entrevistadas (professoras do quinto ao nono ano) as pesquisadoras identificaram a recorrência de elementos como a influência familiar e/ou de um antigo professor, bem como o desejo de trabalhar em uma profissão com a qual se identifica. Além de identificar os fatores que motivaram a escolha da profissão docente, como resultados, a pesquisa acentua a insatisfação das docentes com a intensificação e a desvalorização de seu trabalho, embora afirmem gostar do que fazem.

Outra pesquisa, que também investigou as condições de trabalho docente nos anos finais do Ensino Fundamental em escolas da Rede Estadual de Ensino de Joinville - SC, encontra-se no Banco de dissertações do Programa de Mestrado em Educação da UNIVILLE. De autoria de Lima (2013), intitulada “Condições de trabalho dos docentes dos anos finais do Ensino Fundamental", investigou de que forma as condições de trabalho influenciam na qualidade do exercício docente e como as exigências para o exercício deste ofício tem afetado o trabalho dos professores. 
De forma geral, embora os dados tenham demonstrado que os docentes considerassem as condições de trabalho boas, os resultados da pesquisa sugeriram possibilidades de melhoria quanto à infraestrutura das escolas, remuneração dos professores e cumprimento do tempo dedicado à hora atividade de 33,3\%, conforme determina a legislação nacional, já que na época da pesquisa (2011 e 2012) os professores contavam com apenas $20 \%$ da jornada de trabalho para atividades de planejamento, avaliação e correções (hora atividade), situação que ainda persiste, considerando o tempo destinado à realização de hora atividade.

Contudo, um olhar mais atento aos resultados, deixa claro o descontentamento dos docentes com os salários, com a falta de valorização do trabalho realizado em sala de aula, com a jornada de trabalho que excede o tempo na escola, com a intensificação do trabalho gerada pela digitação de notas e com a pressão em atingir metas de aprovação ao término do ano letivo. Preocupa, também, conforme aponta o autor, a falta de interesse e disciplina dos estudantes, bem como, o descomprometimento das famílias na educação de seus filhos.

As outras pesquisas que complementam este balanço das produções, foram encontradas na Biblioteca Digital de Teses e Dissertações da CAPES, sendo uma delas do ano de 2007 e a outra do ano de 2014.

Na pesquisa intitulada "A intensificação do trabalho docente na rede municipal de Betim", do ano de 2007, o pesquisador Flávio Januzzi da Silva entrevistou professores dos anos finais do Ensino Fundamental de duas escolas municipais. Como objetivo central, buscou analisar o trabalho docente realizado na Rede Municipal de Betim/MG, frente às reformas educacionais que marcam o contexto em questão, identificando situações de intensificação do trabalho docente e aumento nas formas de controle do trabalho, assim como, estratégias de aceitação e enfrentamento de tais situações por parte dos professores. Ficou evidente o processo de proletarização docente e a intensificação do trabalho dos professores, expostos cada vez mais às situações de precarização das condições de trabalho. Embora os docentes apontem a desvalorização salarial e a perda do prestígio social como fatores de descontentamento, assim como nas demais pesquisas, também afirmam gostar do que fazem.

Semelhante aos dados dos professores que participaram da pesquisa de Lima (2013), os depoimentos dos docentes de Betim também revelam o descontentamento com as condições físicas da escola, com o excesso de trabalho levado para casa, com a pressão pela aprovação dos estudantes e pela falta de comprometimento das famílias para com a educação 
de seus filhos. Os entrevistados apontaram também, considerando que a pesquisa aconteceu em 2007, necessidade de preparar atividades específicas para os estudantes com necessidades especiais, frente à falta de profissionais com a formação apropriada para auxiliá-los em sala de aula. O pesquisador Silva percebeu, em seus dados de pesquisa, uma resistência dos docentes às condições de trabalho desfavoráveis, como por exemplo, a demora para ir para a sala de aula após os sinais de início de turno e término de recreio. Ao contrário das demais pesquisas, os resultados desta pesquisa evidenciam o fator violência - física e simbólica presente num contexto marcado pelo tráfico de drogas, bem como o aumento dos índices de adoecimento docente.

Na pesquisa "Precarização das condições de trabalho dos professores do Ensino Fundamental da Rede Estadual de Goiás", de 2014, o pesquisador Carlos Marcelo Martins Carvalho propôs como objetivo central levantar dados que permitissem compreender e analisar o processo de precarização das condições efetivas e materiais de trabalho dos professores do Ensino Fundamental nas escolas da Rede Estadual de Educação em Goiás. Aplicada junto aos professores dos anos finais do Ensino Fundamental, o dados indicaram a flexibilização do trabalho docente no que tange aos direitos trabalhistas obtidos ao longo do tempo, bem como, a intensificação da atividade docente, que juntos contribuem para a precarização das condições de trabalho. Assim como nas pesquisas anteriores, reaparece aqui a sensação de desvalorização por parte dos professores, decorrente do desprestígio social e dos salários, enfatizando ainda, o não cumprimento por parte do Estado da lei que estabelece o piso nacional do magistério quando da realização da pesquisa.

Os resultados evidenciam ainda, que frente aos salários recebidos, muitos professores têm assumido uma carga horária excessiva, comprometendo a gestão do tempo dedicado ao trabalho e à vida pessoal. Assim como na pesquisa de Lima (2013), a estrutura física aparece como um dos fatores mais preocupantes. No caso de Goiás, a situação informada pelos participantes da pesquisa mostrava-se dramática, considerando uma realidade marcada por reformas prediais e espaços inapropriados alocados temporariamente para o funcionamento das unidades escolares. Em Goiás, em 2014, assim como em Betim, em 2007, também predominam fatores como o adoecimento docente e a ausência de profissionais habilitados para atender os estudantes com necessidades especiais. Outro elemento presente na fala dos professores é a flexibilização dos contratos de trabalho, caracterizada pela enorme quantidade de profissionais contratados, decorrência da falta de concurso público para o 
magistério. No quesito resistência, o pesquisador cita a incidência de greves no período compreendido entre os anos de 2008 e 2012, objetivando principalmente, garantir o cumprimento do pagamento do Piso Nacional do Magistério pelo Estado.

Após a análise e comparação dos resultados das quatro pesquisas sobre condições de trabalho docente nos anos finais do Ensino Fundamental, é possível concluir que, em síntese, embora seja possível verificar muitas semelhanças e algumas divergências, predomina um cenário marcado por situações que acentuam o processo de precarização das condições de trabalho, caracterizada pela intensificação das condições de trabalho e desvalorização dos professores, bem como, a intensificação da proletarização docente, marcada pela flexibilização dos contratos de trabalho.

\section{CONSIDERAÇÕES FINAIS}

Relembrando as palavras que concluem a introdução deste artigo, de acordo com André (2010), de 298 estudos analisados em 2007, apenas 10 (3\%) focalizaram as condições de trabalho docente. Esta realidade ficou evidente quando feita a realização do balanço das produções acerca da temática "condições de trabalho docente nos anos finais do Ensino Fundamental", conforme citado anteriormente.

Embora tenham sido encontradas apenas quatro pesquisas sobre a temática aqui referenciada, é possível identificar inúmeras semelhanças e algumas divergências, considerando o espaço de tempo compreendido entre as pesquisas realizadas por Silva (2007) e Carvalho (2014).

Entre as semelhanças encontradas, podem ser citadas a precarização das condições de trabalho docente, relacionadas com a contínua intensificação das condições de trabalho e desvalorização, bem como, a flexibilização dos contratos de trabalho, que por sua vez, relacionam-se com o processo de proletarização do trabalho docente "[...] processo pelo qual um grupo de trabalhadores perde, mais ou menos sucessivamente, o controle sobre seus meios de produção, o objetivo de seu trabalho e a organização de sua atividade" (ENGUITA, 1991 apud SILVA, 2007, p.104).

Sobre as divergências, pode ser apontada a violência, recorrente na fala dos entrevistados por Silva (2007) e o adoecimento dos professores, que aparece em maior grau 
nas pesquisas de Silva (2007) e Carvalho (2014). Também ficou clara a resistência dos professores ao recrudescimento das condições de trabalho docente, de forma coletiva ou por meio de atitudes individuais que transgridem a rotina diária.

Frente às semelhanças e às divergências que marcam o contexto vivenciado pelos professores inseridos nos diferentes contextos que marcam a realidade de escolas municipais e estaduais de estados brasileiros, conforme discutido até aqui, finalizamos este artigo reforçando a fala de André (2010) sobre a necessidade da realização de pesquisas sobre as condições de trabalho docente, em especial, nos anos finais do Ensino Fundamental.

\section{REFERENCIAS BIBLIOGRÁFICAS}

ALVEZ, B. P.;SILVA, J. C. S.; FERREIRA, L. S.. Considerações acerca do trabalho dos professores a partir de uma investigação com professoras de uma escola municipal de Santa Maria - In: VIII ENCONTRO DE PESQUISA EM EDUCAÇÃO DA REGIÃO SUL ANPED, 2010, Londrina.Paraná: Universidade Estadual de Londrina, 2010. p. 01-16. Disponível em: < http://www.portalanpedsul.com.br/2010/ >. Acesso em: 15 maio 2015.

ANDRÉ, Marli. Formação de professores: um campo de estudos. Revista Educação da Pontifícia Universidade Católica do Rio Grande do Sul - PUC RS. Porto Alegre, v.33, n.3, set/dez de 2010, p. 174-181.

BORGES, Cecília. Trabalho Coletivo. In: OLIVEIRA, Dalila Andrade; DUARTE, Adriana Cancella; VIEIRA, Lívia Fraga (Org.). Dicionário trabalho, profissão e condição docente. Belo Horizonte: Ed. da UFMG, 2010. Disponível em: <http://www.gestrado.org/>. Acesso em: 15 maio 2015.

BRASIL, LDB. Lei 9394/96 - Lei de Diretrizes e Bases da Educação Nacional. Disponível em < http://portal.mec.gov.br/arquivos/pdf/ldb.pdf>. Acesso em: 15 Maio de 2015. 
CARVALHO, Carlos Martins. Precarização das condições de trabalho dos professores do Ensino Fundamental da Rede Estadual de Goiás. 2014. vi, 172 f. Dissertação de mestrado (Mestrado em Educação) - Pontificia Universidade Católica de Goiás, 2014.

FERNANDES, Anielle Cireno e HELAL, Diogo Henrique. Precarização do trabalho. In: OLIVEIRA, Dalila Andrade; DUARTE, Adriana Cancella; VIEIRA, Lívia Fraga (Org.). Dicionário trabalho, profissão e condição docente. Belo Horizonte: Ed. da UFMG, 2010. Disponível em: <http://www.gestrado.org/>. Acesso em: 15 maio 2015.

FRIGOTTO, Gaudêncio. Trabalho. In: OLIVEIRA, Dalila Andrade; DUARTE, Adriana Cancella; VIEIRA, Lívia Fraga (Org.). Dicionário trabalho, profissão e condição docente. Belo Horizonte: Ed. da UFMG, 2010. Disponível em: 〈http://www.gestrado.org/>. Acesso em: 15 maio 2015.

LIMA, Fernando de. Condições de trabalho dos docentes dos anos finais do ensino fundamental. 2013. vi, 173 f. Dissertação de mestrado (Mestrado em Educação) Universidade da Região de Joinville, 2013.

MARIN, Alda Junqueira. Precarização do Trabalho Docente. Condições de Trabalho Docente. In: OLIVEIRA, Dalila Andrade; DUARTE, Adriana Cancella; VIEIRA, Lívia Fraga (Org.). Dicionário trabalho, profissão e condição docente. Belo Horizonte: Ed. da UFMG, 2010. Disponível em: <http://www.gestrado.org/>. Acesso em: 15 maio 2015.

OLIVEIRA, Dalila Andrade. Trabalho Docente.In: OLIVEIRA, Dalila Andrade; DUARTE, Adriana Cancella; VIEIRA, Lívia Fraga (Org.). Dicionário trabalho, profissão e condição docente. Belo Horizonte: Ed. da UFMG, 2010. Disponível em: 〈http://www.gestrado.org/>. Acesso em: 15 maio 2015.

OLIVEIRA, Dalila Andrade e ASSUNÇÃO, Ada Ávila. Condições de Trabalho Docente.In: OLIVEIRA, Dalila Andrade; DUARTE, Adriana Cancella; VIEIRA, Lívia Fraga (Org.). Dicionário trabalho, profissão e condição docente. Belo Horizonte: Ed. da UFMG, 2010. Disponível em: <http://www.gestrado.org/>. Acesso em: 15 maio 2015. 
SILVA, Flávio Januzzi.A intensificação do trabalho docente na rede municipal de Betim. 2007. vi, 202 f. Dissertação de Mestrado (Mestrado em Educação) - Universidade Federal de Minas Gerais. 2007.

${ }^{1}$ Mestrando em Educação. Universidade da Região de Joinville - UNIVILLE , Joinville, SC. E-mail: ajfricardo@ig.com.br

${ }^{2}$ Doutora em Educação, PUC- SP. Professora do Programa de Mestrado em Educação da Universidade da Região de Joinville (UNIVILLE). E-mail: gmhobold@terra.com.br

RECEBIDO EM: Setembro de 2015

APROVADO EM: Abril de 2016 